\title{
A Comparative Expected Value Analysis Study to Determine If the Economic Benefits of Screening and Early Diagnosis Treatment of the Most Common Types of Cancer in the United States Provide Economic Value
}

\author{
S. Eric Anderson', Kim-Liang Chuah ${ }^{2}$ \\ ${ }^{1,2}$ La Sierra University, Riverside, California
}

\begin{abstract}
Breast, colorectal and skin cancer screening and early diagnosis with treatment provides economic value, while lung cancer screening and early diagnosis with treatment came close to providing economic value. Bladder, endometrial, kidney, leukemia, non-Hodgkin lymphoma, pancreatic, prostate and thyroid cancer screening and early diagnosis with treatment were not found to have provided economic value.
\end{abstract}

KEYWORDS: Cancer, cost to screen, positivity rate, expected cost to treat, early diagnosis treatment cost, late diagnosis treatment cost, and economic benefit.

\section{INTRODUCTION}

Cancer is the second leading cause of death in the United States and in the year 2020 over 1.8 million cancer cases were projected to be diagnosed and over 600 thousand were projected to die from the disease (American Cancer Society, 2020). The cost to treat cancer was $\$ 150.8$ billion (excludes oral drugs) in 2018 (National Cancer Institute, 2020) and in 2015 there was $\$ 94.4$ billion in lost earnings by those diagnosed with cancer (Islami et al, 2019).

Earlier stage treatment costs can be up to four times less expensive than later stage diagnosis and earlier stage treatment is often less invasive resulting in shorter treatment times and lower patient costs (WHO, 2017). In the United States, stage IV cancer represents $18 \%$ of all diagnoses and $48 \%$ of cancer-related deaths (Clark et al, 2020). Clark et al (2020) estimated $15 \%$ fewer cancer-related deaths if stage IV patients had been diagnosed in stage III. The annual costsavings in the United States from early stage cancer diagnosis was $\$ 26$ billion (Kakushadze et al, 2017)

The US Preventive Services Task Force (2020) currently recommends age and population-based screening for cervical, colorectal, breast, prostate as well as lung cancer screening for current and former heavy smokers. Population-based screening for breast cancer (Ahern et al, 2009), colon cancer (Ran et al, 2019) cervical cancer (Esselen, 2013) was found to be cost-effective. Prostate cancer screening every 4 years was also found to be cost-effective (de Carvalho et al, 2018). Screening for hepatitis B or C infection as well as cirrhosis is also recommended in targeting hepatocellular cancer (Marrero et al, 2018).
The cancer death rate fell 29\% from 1991- 2017, which resulted in 2.9 million fewer deaths and the 5-year survival rate for all cancers rose from $49 \%$ in 1975 to $69 \%$ in 2015

(American Cancer Society, 2020). The decline in cancer deaths was mostly due to smoking-cessation programs, screening and an improvement in treatments (Siegel, 2020). Improvement in mortality was due to cancer screening for people with an average risk for breast, cervical, colorectal, prostate, and lung cancers (Brill, 2020).

The 5-year survival rate for patients diagnosed with metastatic lung cancer is 5\% versus $57 \%$ for those patients who have been diagnosed in an early stage when the cancer is localized (Siegel, 2020). However, identifying cancer at an earlier stage when the cancer is potentially more treatable comes with risks such as internal bleeding complications from invasive procedures (Kim et al, 2019), false-negative as well as false-positive results (American Cancer Society, 2020) and the over diagnosis of early cancers or precancerous lesions that might have never advanced, leading to overtreatment (National Cancer Institute, 2018) and excess spending.

The most effective way to identify early-stage cancer is by screening asymptomatic individuals (Ahlquist, 2018). Intuitively, screening resulting in earlier stage diagnosis when the cancer is more likely to respond to treatment seems to make sense. However, there are no population-based screening recommendations for the majority of cancers in average-risk patients, most of which are not diagnosed until the later stages (Brill, 2020). Therefore, the purpose of this study is to determine if cancer screening and an earlier stage diagnosis reduces mortality rates and medical costs and if so what types of cancer screening provide economic value. 


\section{"A Comparative Expected Value Analysis Study to Determine If the Economic Benefits of Screening and Early Diagnosis Treatment of the Most Common Types of Cancer in the United States Provide Economic Value"}

\section{RESULTS}

Bladder Cancer - The United States Preventive Services Task Force (2021) concludes that there is no evidence to support that the screening benefits exceed the costs in identifying bladder cancer in asymptomatic adults. A total of $1.3 \%$ of those screened received a diagnosis of bladder cancer, including $0.06 \%$ with a muscle-invasive cancer (Chou, 2010). The use of renal ultrasound with cystoscopy had an incremental cost per cancer detected of $\$ 50,000$, while the incremental cost per cancer detected was $\$ 6.5$ million with a CT scan and cystoscopy (Halpern et al, 2017). The replacement of the renal ultrasound with a CT scan detected just one more malignancy per 10,000 screened patients (Halpern et al, 2017). The cost to treat patients in the highest intensity quartile $(\$ 7,131)$ is nearly three times more than the cost to treat bladder cancer patients in the lowest quartile $(\$ 2,830)$ even after adjusting for differences in disease severity (Hollenbeck, 2009). Therefore, the expected cost to screen and treat early diagnosed bladder cancer is $\$ 52,830$ $(\$ 50,000+\$ 2,830)$ and the cost to treat late diagnosed bladder cancer is $\$ 7,131$ resulting in a $\$ 45,699$ economic cost for bladder cancer screening.

Breast Cancer - The United States Preventive Services Task Force (2021) recommends biennial screening mammography for women starting at age 50 years and continuing until age 74. About $10 \%$ of women who receive a mammogram will get called back for further testing and eventually after further analysis only about $0.5 \%$ ( 1 in 200) tested positive for cancer (O'Connell, 2015). The American Cancer Society (2019) also reported that about $10 \%$ are called back for additional tests following their initial mammogram and of that percentage only $10 \%$ are biopsied and $20 \%$ of biopsies come back positive. MDSave (2020) reported that the national average cost for a mammogram is $\$ 214$ so the expected cost to screen would be $\$ 42,800$ ( $\$ 214 / .005$ ). There is also the issue of false negatives and positives. Mammography correctly identifies $87 \%$ of women who have breast cancer or misses about $13 \%$ who have it (BCSC, 2017). The average costs of breast cancer treatment within the first year after receiving a diagnosis were as follows: Stage 0: $\$ 60,637$, Stage I/II: $\$ 82,121$, Stage III: $\$ 129,387$ and Stage IV: $\$ 134,682$ (Elder, 2017 \& Blumen et al, 2016). Therefore, the expected cost to screen and treat early diagnosed breast cancer is $\$ 103,437$ $(\$ 42,800+\$ 60,637)$ and the cost to treat later diagnosed cancer is $\$ 115,396(\$ 82,121+\$ 129,387+\$ 134,682 / 3)$ so there would be an $\$ 11,959$ economic benefit for breast cancer screening.

Colorectal Cancer - The United States Preventive Services Task Force (2021) recommends screening for colorectal cancer starting at age 50 years and continuing until age 75 years. On average individuals should get a colonoscopy at 50, 60 , and 70 years of age or roughly 3 times in their lifetime. The average clinical cost for screening and diagnostic services per person served was $\$ 1,150$ for colonoscopy-based programs, compared to $\$ 304$ for fecal occult blood tests or immune-chemical tests (Subramanian et al, 2016). Therefore, the total recommended lifetime costs per individual for colonoscopy's is $\$ 3,450(\$ 1,150 * 3)$. According to the American Cancer Society (2021) the overall lifetime risk of developing colorectal cancer is: about 1 in 23 (4.3\%) for men and 1 in 25 (4.0\%) for women. Colon cancer is found in four-tenths of one percent of all screening colonoscopies and about $40 \%$ of the time a precancerous polyp is found and removed during a screening colonoscopy (Sand, 2020). The median estimated lifetime costs per capita was $\$ 25,369$ for patients with early-stage (stages I and II) tumors, while the median costs were $\$ 97,503$ for patients with late-stage (stages III and IV) tumor (Eaglehouse et al, 2019). The cost for patients who had surgical treatment was $\$ 19,944$ and the cost for patients who had surgery and radiation or chemotherapy was $\$ 100,404$ (Eaglehouse et al, 2019). Polyps less than 1 centimeter in size have less than a $1 \%$ chance of becoming cancerous, but those with two centimeters or greater have a $40 \%$ chance of becoming cancerous (WebMD, 2021). Therefore, the expected cost to remove the polyps before they become cancerous is $\$ 95,156,830(\$ 80,232+$ $\$ 14,924)$ and the cost to treat late stage diagnosed colorectal cancer is $\$ 100,404$ so there would be a $\$ 5,248$ economic benefit for colorectal cancer screening.

Endometrial Cancer - The United States Preventive Services Task Force (2021) does not recommend annual screening for endometrial cancer. The American Cancer Society (2019) estimated the number of new cases of endometrial cancer was 61,880 and the number of deaths was 12,160 in the United States, which is not a high number considering that there are more than 30 million women over the age of 60 . This means there is only a 1 in 200 chance $(61,880 / 30,000,000)$ of getting endometrial cancer. An ultrasound, a blood test and an endometrial biopsy to monitor the uterus and ovaries costs around $\$ 1,500$ on MDSave. There is no standard or routine screening test for endometrial cancer, but this type of cancer causes symptoms such as vaginal bleeding so it is often found at an early stage. Since endometrial cancer is usually diagnosed and treated at an early stage there is a good chance of recovery (American Cancer Society, 2019). Cardiovascular disease is the most common cause of death in patients with endometrial cancer because of the related metabolic risk factors (Ward et al, 2012). An abdominal hysterectomy is a common treatment procedure and reduces the risk of endometrial cancer. According to MDSave, the cost of an abdominal hysterectomy ranges $\$ 7,316$ to $\$ 15,727$ and averages $\$ 13,421$. Therefore, the expected cost to screen and treat early diagnosed endometrial cancer is $\$ 763,421$ $(\$ 750,000+\$ 13,421)$ and the cost to treat late diagnosed endometrial cancer is $\$ 13,421$ so there would be a $\$ 750,000$ economic cost for endometrial cancer screening. 


\section{"A Comparative Expected Value Analysis Study to Determine If the Economic Benefits of Screening and Early Diagnosis Treatment of the Most Common Types of Cancer in the United States Provide Economic Value"}

Kidney Cancer - The United States Preventive Services Task Force (2021) concludes that the current evidence is insufficient to assess the balance and harms of a clinician screening for kidney cancer in asymptomatic adults. A renal function panel costs about $\$ 72$ in the United States (FarivarMohseni, 2006). However, there is no test that has been shown to lower the overall risk of dying from kidney cancer (Cancer.org, 2020). There are tests that can find some kidney cancers early, but none are recommended to screen for kidney cancer in people with average risk (Cancer.org, 2020). CT screening identified one malignant mass for every 371 people screened and $\$ 123$ million was spent screening to identify 1,396 tumors at a cost of $\$ 88,000$ per tumor identified (Ekwueme et al, 2008). Surgical treatment of small renal tumors has a 5-year cancer specific mortality-free rate of 97.5\% (Crépel, 2010). If a renal mass is identified early, treatment is usually curative. The 5-year survival rate with localized renal cancer is $91 \%$ but with distant spread the survival rate is $11 \%$ (Howlader, 2009) reflecting the slow natural progress of the disease and effectiveness of surgical treatment. Given the slow average growth rate of renal masses, 5-yearly screening would be likely to pick up most cancers at a treatable stage. The harm of overtreatment might outweigh the benefits of screening, particularly in populations with a reduced life-expectancy (Patel et al, 2012). The treatment of renal masses would not be of net benefit in older populations (Parkinson, 2006). MDSave reported that Kidney cancer treatment typically costs $\$ 15,000-\$ 75,000$ or more for a nephrectomy, a kidney removal surgery, which depends on the extent of the surgery and whether there are complications. Another cost comparison site Vimo.com reported that the average list price for kidney removal was more than $\$ 25,000$ while the average negotiated price, through an insurance company, was about $\$ 8,000$. Therefore, the expected cost to screen and treat early diagnosed kidney cancer is $\$ 113,000(\$ 88,000+\$ 25,000)$ and the cost to treat late diagnosed kidney cancer is $\$ 25,000$ so there would be an $\$ 88,000$ economic cost for kidney cancer screening. The M.D. Anderson Cancer Center (2020) reported that a kidney transplant can cost $\$ 260,000$ or more once the pre-transplant screening, donor matching, surgery, post-surgical care and first six months of drugs are summed.

Leukemia - The United States Preventive Services Task Force (2021) concludes that the current evidence is insufficient to assess the balance and harms of a clinician screening for leukemia in asymptomatic adults. There is not a screening test that has been proven to be reliable enough to detect leukemia in its earliest stages prior to the symptoms (WebMD, 2020). While there are no tests specifically designed for leukemia screening, the condition may be detected through a chest Xray or CAT scan, spinal tap or a bone marrow aspiration and biopsy (WebMD, 2020). If the patient tests positive for leukemia, then the doctor will perform a bone marrow biopsy to determine the patient's leukemia type (WebMD, 2020). Once diagnosed the doctor may recommend delaying treatment if the patients is healthy, has no bothersome B-cell lymphoma symptoms, small lymph nodes, doesn't have lymphoma in any of the major organs (heart, lungs, kidneys, etc.) or is over the age of 70 (WebMD, 2020). Delaying treatment delays the side effects of chemotherapy drugs, which cause hair loss, nausea, mouth sores, fatigue and skin blisters (WebMD, 2020). Further, sometimes lymphoma cells no longer respond to the chemotherapy drugs or other therapy, but when treatment is delayed the cancer cells can't become as resistant (WebMD, 2020). For those diagnosed with slow-growing types of B-cell lymphoma, there may be no difference in the way the disease develops between immediate treatment and delaying treatment as long as the patient gets regular check-ups (WebMD, 2020). Even though research shows that delaying treatment can be just as helpful as active treatment, there are risks of delaying since it could allow the cancer to grow and affect one's odds of surviving (WebMD, 2020). Most people with B-cell lymphoma will eventually need to be treated, but if the patient has a slowgrowing lymphoma that isn't causing symptoms, the delaying treatment may be best (WebMD, 2020).

Lung Cancer - The United States Preventive Services Task Force (2021) recommends annual screening for lung cancer with low-dose computed tomography (LDCT) in adults aged 55 - 80 who have a 30 pack-year smoking history and currently smoke or have quit within the past 15 years. A spiral CT scan costs $\$ 300$ and is covered by insurance for patients in the high risk for developing lung cancer category. However, only around $2 \%$ of eligible smokers have sought the free scans (Black et al, 2014). As a result, by the time lung cancer causes symptoms, such as chronic cough or difficulty breathing, it is usually in an advanced stage when it is more difficult to treat. As a result, the $4 \%$ of patients with a diagnosis of lung cancer, only have an incremental life expectancy was 1.6 years (Black et al, 2014) since nearly half of all those diagnosed with lung cancer were in the advanced stages (Zappa and Mousa, 2016). According to Gilda et al (2017), the total health care costs and utilization after lung cancer diagnosis were significantly higher among patients diagnosed at Stage IV $(\$ 21,441)$ than they were for patients diagnosed at Stage I $(\$ 7,239)$. Earlier diagnosis treatment costs were estimated to be $\$ 14,340(\$ 21,441+\$ 7,239 / 2)$ since the spiral CT scan would only provide economic benefit to $50 \%$ of those screened since half of the patients screened were in the advanced stages of lung cancer so the expected cost to screen would be $\$ 7,500$ ( $\$ 300 / .02 / 2)$. Black et al (2017) reported that 217 high-risk smokers would have to undergo a CT lung scan for one to be spared death from lung cancer. Therefore, the expected cost to screen and treat early diagnosed lung cancer is $\$ 21,840(\$ 7,500+\$ 14,340)$ and the cost to treat late diagnosed lung cancer is $\$ 21,441$ so there would be a $\$ 399$ economic cost for kidney cancer screening. 


\section{"A Comparative Expected Value Analysis Study to Determine If the Economic Benefits of Screening and Early Diagnosis Treatment of the Most Common Types of Cancer in the United States Provide Economic Value"}

Non-Hodgkin lymphoma - The United States Preventive Services Task Force (2021) has not assessed the costs and benefits for clinical screening for non-Hodgkin lymphoma in asymptomatic adults. Even though there is no routine lymphoma screening test, early detection is possible for both Hodgkin and non-Hodgkin lymphoma (Cancer.org, 2021). The typical diagnostic process involves a physical exam and medical history, along with a biopsy and cell/blood tests. There are no widely recommended screening tests for non-Hodgkin lymphoma, because no screening test has been shown to lower the risk of dying from this cancer (Cancer.Org, 2021). More often symptoms are caused by something other than lymphoma, but it's important for the patients to have them checked by a doctor if they aren't going away or are getting worse. Careful, regular medical checkups are important for people with known risk factors for nonHodgkin lymphoma, such as HIV infections, organ transplants, autoimmune disease, or prior cancer treatment (Cancer.Org, 2021).

Pancreatic Cancer - The United States Preventive Services Task Force (2021) recommends against screening for pancreatic cancer in asymptomatic adults. There is no single test that diagnosis for pancreatic cancer. Definitive diagnosis requires a series of imaging scans, blood tests and biopsy, which are typically if the patient has symptoms. Since early pancreatic cancer does not usually show symptoms, the cancer has likely grown and even spread to other organs. According to the American Cancer Society (2020), none of the available tests have proven to actually lower the risk of dying from the disease since only $20 \%$ of patients are alive a year after diagnosis and after five years only $7 \%$ are still living (Yu et al, 2015). Once pancreatic cancer becomes detectable clinically progression from low-stage to advancedstage disease is rapid. Patients with a stage I cancer diagnosis were on average 1.3 years removed from a stage IV cancer diagnosis (Yu et al, 2015).

Prostate Cancer - The United States Preventive Services Task Force (2021) recommends PSA-screening for prostate cancer in men aged 55 to 69 . Screening offers a small potential benefit of reducing the chance of death from prostate cancer in men over the age of 70 (Mayo Clinic, 2019). Falsepositives often result in additional testing and possible prostate biopsy, overtreatment and treatment complications, such as incontinence and erectile dysfunction (Mayo Clinic, 2019). The low-risk, slow-growing prostate cancer is often unlikely to harm a man before he dies of other causes (Mayo Clinic, 2019). The cost for a PSA test is about $\$ 40$. If the test yields an abnormal result, then the costs start adding up as the doctor will usually refer to a urologist for a biopsy resulting a consultation fee (up to $\$ 350$ ), an ultrasound fee (about $\$ 150$ ), additional professional fees (up to \$200) and biopsy fees (about \$500). If 100 men over age 50 take the PSA test: 85 will have a normal PSA and 15 will have a higher than normal
PSA and require further tests (Mayo Clinic, 2019). After further testing, results will show that 12 do not have prostate cancer, but 3 will have it (Mayo Clinic, 2019). However, studies have shown that between 23 to $42 \%$ of men with prostate cancer detected by PSA tests will not have symptoms during their lifetimes (Mayo Clinic, 2019). For an American male, the lifetime risk of developing prostate cancer is 1 in 6 , but the risk of dying of prostate cancer is only $2.9 \%$ ( 1 in 34 ). Men in their 50s who died from other causes have shown a $30-45 \%$ prevalence of prostate cancer while men in their $70 \mathrm{~s}$ have shown an $80 \%$ prevalence rate of prostate cancer (Mayo Clinic, 2019). The median treatment cost per patient within 3 years following prostate cancer diagnosis was $\$ 14,452$, with treatment costs accounting for the $\$ 10,558$ (Rosenberg, 2018). The treatment cost ranged from $\$ 19,901$ for low-risk disease robot-assisted prostatectomies to $\$ 50,276$ for highrisk disease treatment that includes radiation therapy (Bardi, 2013). Therefore, the expected cost to screen and treat early diagnosed prostate cancer is $\$ 81,901(\$ 62,000+$ $\$ 19,901)$ and the cost to treat late diagnosed prostate cancer is $\$ 50,276$ so there would be a $\$ 31,625$ economic cost for prostate cancer screening.

Skin Cancer - The United States Preventive Services Task Force (2021) concludes that the current evidence is insufficient to assess the balance and harms of visual skin examination by a clinician to screen for skin cancer in asymptomatic adults. MDSave.com reported that the national average for a skin biopsy is $\$ 536$ and $4.1 \%$ of biopsy test positive for invasive melanoma (Piepkorn et al, 2021). Losina et al (2007) found that that the average treatment costs for skin cancers to range from $\$ 1,732$ for stage I disease to $\$ 56,059$ for stage IV disease. Therefore, the expected cost to screen $\$ 13,073$ (\$536/.041) and treat $(\$ 1,732)$ early diagnosed skin cancer is $\$ 14,805$ and the cost to treat late stage diagnosed skin cancer is $\$ 56,059$ so there would be a $\$ 41,254$ economic benefit for skin cancer screening.

Thyroid Cancer - The United States Preventive Services Task Force (2021) doesn't recommend thyroid cancer screening in asymptomatic adults. The total cost for the surveillance tests and procedures per patient in the low, intermediate and high risk groups were $\$ 1,225, \$ 1,760$ and $\$ 2,774$ respectively and the cost was $\$ 149,619$ to detect in the low risk group, $\$ 22,434$ in the intermediate risk group and $\$ 20,680$ in the high risk group (American Thyroid Association, 2016). The cost for low-risk thyroid cancer undergoing thyroidectomy or neck dissection, which included initial surgery, follow-up, and treatment of recurrence were between $\$ 13,896$ and $\$ 14,241$ for total thyroidectomy and between $\$ 15,037$ and $\$ 15,063$ for hemi-thyroidectomy (Shrime et al, 2007). Therefore, the expected cost to screen and treat early diagnosed thyroid cancer is $\$ 164,178(\$ 149,619+\$ 14,559)$ and the cost to treat late diagnosed thyroid cancer is $\$ 115,680(\$ 95,000+$ 


\section{"A Comparative Expected Value Analysis Study to Determine If the Economic Benefits of Screening and Early}

Diagnosis Treatment of the Most Common Types of Cancer in the United States Provide Economic Value"

$\$ 20,680$ ) so there would be a $\$ 48,498$ economic cost for thyroid cancer screening.

\section{RESULTS}

The expected cost to screen and treat early stage diagnosed bladder cancer is $\$ 52,830(\$ 50,000+\$ 2,830)$ and the cost to treat late stage diagnosed bladder cancer is $\$ 7,131$ so there would be a $\$ 45,699$ economic cost screening for bladder cancer. The expected cost to screen and treat early stage diagnosed breast cancer is $\$ 103,437(\$ 42,800+\$ 60,637)$ and the cost to treat late stage diagnosed bladder cancer is $\$ 115,396$ so there would be an $\$ 11,959$ economic benefit screening for breast cancer. The expected cost to screen and treat early stage diagnosed colorectal cancer is $\$ 95,156,830$ $(\$ 80,232+\$ 14,924)$ and the cost to treat late stage diagnosed colorectal cancer is $\$ 100,404$ so there would be a $\$ 5,248$ economic benefit for colorectal cancer screening. The expected cost to screen and treat early stage diagnosed endometrial cancer is $\$ 763,421(\$ 750,000+\$ 13,421)$ and the cost to treat late stage diagnosed endometrial cancer is $\$ 13,421$ so there would be a $\$ 750,000$ economic cost for endometrial cancer screening.

\begin{tabular}{|c|c|c|c|c|}
\hline $\begin{array}{c}\text { Types of } \\
\text { Cancer }\end{array}$ & $\begin{array}{c}\text { Cost to } \\
\text { Screen }\end{array}$ & $\begin{array}{c}\text { Positivity } \\
\text { Rate }\end{array}$ & $\begin{array}{c}\text { Expected } \\
\text { Cost } \\
\text { Screen }\end{array}$ & $\begin{array}{c}\text { Early Stage } \\
\text { Treatment } \\
\text { Cost }\end{array}$ \\
\hline Bladder & - & 1.300 & $\$ 50,000$ & $\$ 2,830$ \\
\hline Breast & $\$ 214$ & 0.005 & $\$ 42,800$ & $\$ 60,637$ \\
\hline Colon & $\$ 3,450$ & 0.043 & $\$ 80,232$ & $\$ 14,924$ \\
\hline Endom & $\$ 1,500$ & 0.002 & $\$ 750,000$ & $\$ 13,421$ \\
\hline Kidney & - & - & $\$ 88,000$ & $\$ 25,000$ \\
\hline Leukem & - & - & - & - \\
\hline Lung & $\$ 300$ & 4.000 & $\$ 7,500$ & $\$ 14,340$ \\
\hline NH lym & - & - & - & - \\
\hline Pancrea & - & - & - & - \\
\hline Prostate & $\$ 1,240$ & 2.000 & $\$ 62,000$ & $\$ 19,901$ \\
\hline Skin & $\$ 536$ & 4.100 & $\$ 13,073$ & $\$ 1,732$ \\
\hline Thyroid & - & - & $\$ 149,619$ & $\$ 14,559$ \\
\hline
\end{tabular}

The expected cost to screen and treat early stage diagnosed kidney cancer is $\$ 113,000(\$ 88,000+\$ 25,000)$ and the cost to treat late stage diagnosed kidney cancer is $\$ 25,000$ so there would be an $\$ 88,000$ economic cost for kidney cancer screening. The expected cost to screen and treat early stage diagnosed lung cancer is $\$ 21,840(\$ 7,500+\$ 14,340)$ and the cost to treat late stage diagnosed lung cancer is $\$ 21,441$ so there would be a $\$ 399$ economic cost for kidney cancer screening. The expected cost to screen and treat early stage diagnosed prostate cancer is $\$ 81,901(\$ 62,000+\$ 19,901)$ and the cost to treat late stage diagnosed prostate cancer is $\$ 50,276$ so there would be a $\$ 31,625$ economic cost for prostate cancer screening. The expected cost to screen and treat early stage diagnosed skin cancer is $\$ 14,805(\$ 13,073+$ $\$ 19,901)$ and the cost to treat late stage diagnosed skin cancer is $\$ 56,059$ so there would be a $\$ 41,254$ economic benefit for

2312 skin cancer screening. The expected cost to screen and treat early stage diagnosed thyroid cancer is $\$ 164,178(\$ 149,619+$ $\$ 14,559)$ and the cost to treat late stage diagnosed thyroid cancer is $\$ 115,680$ so there would be a $\$ 48,498$ economic cost for thyroid cancer screening.

\begin{tabular}{|c|c|c|c|c|}
\hline $\begin{array}{c}\text { Types of } \\
\text { Cancer }\end{array}$ & $\begin{array}{c}\text { Screen \& } \\
\text { Early Stage } \\
\text { Treatment } \\
\text { Cost }\end{array}$ & $\begin{array}{c}\text { Late stage } \\
\text { Diagnosis } \\
\text { Treatment } \\
\text { Cost }\end{array}$ & $\begin{array}{c}\text { Economic } \\
\text { Benefit }\end{array}$ & $\begin{array}{c}\text { US } \\
\text { PT } \\
\text { F }\end{array}$ \\
\hline Bladder & $\$ 52,830$ & $\$ 7,131$ & $(\$ 45,699)$ & $\mathrm{I}$ \\
\hline Breast & $\$ 103,437$ & $\$ 115,396$ & $\$ 11,959$ & $\mathrm{BCI}$ \\
\hline Colon & $\$ 95,156$ & $\$ 100,404$ & $\$ 5,248$ & $\mathrm{AC}$ \\
\hline Endom & $\$ 763,421$ & $\$ 13,421$ & $(\$ 750,000$ & $\mathrm{I}$ \\
\hline Kidney & $\$ 113,000$ & $\$ 25,000$ & $(\$ 88,000)$ & $\mathrm{I}$ \\
\hline Leuk & - & - & - & $\mathrm{I}$ \\
\hline Lung & $\$ 21,840$ & $\$ 21,441$ & $(\$ 399)$ & $\mathrm{B}$ \\
\hline NH lym & - & - & - & $\mathrm{I}$ \\
\hline Pancrea & - & - & - & $\mathrm{D}$ \\
\hline Prostate & $\$ 81,901$ & $\$ 50,276$ & $(\$ 31,625)$ & $\mathrm{CD}$ \\
\hline Skin & $\$ 14,805$ & $\$ 56,059$ & $\$ 41,254$ & $\mathrm{I}$ \\
\hline Thyroid & $\$ 164,178$ & $\$ 115,680$ & $(\$ 48,498)$ & $\mathrm{D}$ \\
\hline
\end{tabular}

\section{CONCLUSION}

From a purely cost-saving analysis, by comparing screening and early stage treatment costs versus late stage treatment costs, it is found that there is economic benefit in promoting regular screening for early detection and treatment in breast, colorectal, and skin cancers, while there are currently no cost savings in early detection in the other cancers. Nevertheless, depending on fatality rates and chances of recovery in early detection, the value of lives saved from recovery due to early detection of the other cancers continues to drive the desire for early screening and detection. It is therefore beneficial to continue research and development into more efficient and less costly methods of screening and treatments to increase the economic benefit for all cancers.

\section{REFERENCES}

1. Ahern $\mathrm{CH}$, Shen Y. Cost-effectiveness analysis of mammography and clinical breast examination strategies: a comparison with current guidelines. Cancer Epidemiol Biomarkers Prev. 2009; 18 (3):718-725.

2. Ahlquist DA. Universal cancer screening: revolutionary, rational, and realizable. NPJ Precis Oncol. 2018; 2:23.

3. American Thyroid Association, Thyroid Cancer, Detecting recurrence of papillary thyroid cancer costs much more in those with low-risk than high risk cancer, Clinical Thyroidology for the Public, 2016, 9,2, 10-11

4. American Cancer Society: Cancer Facts and Figures, American Cancer Society, 2019 
"A Comparative Expected Value Analysis Study to Determine If the Economic Benefits of Screening and Early Diagnosis Treatment of the Most Common Types of Cancer in the United States Provide Economic Value"

5. American Cancer Society, Key Statistics for Colon Cancer, 2021.

6. American Cancer Society. Mammograms. Revised October 3, 2019.

7. American Cancer Society. Cancer Facts \& Figures, 2020.

8. Bardi J, How Prostate Cancer Therapies Compare by Cost and Effectiveness, UCSF Report, January 4, 2013

9. Black WC, Gareen IF, Soneji SS, Sicks JD, Keeler EB, Aberle DR, Naeim A, Church TR, Silvestri GA, Gorelick $\mathbf{J}$ and Gatsonis, C, Cost-Effectiveness of CT Screening in the National Lung Screening Trial, N Engl J Med 2014; 371:1793-1802

10. Blumen H, Fitch K, Polkus V, Comparison of treatment costs for breast cancer by tumor stage and type of Service, Am Health Drug Benefits. 2016 Feb; 9(1): 23-32.

11. Breast Cancer Surveillance Consortium - BCSC (2017). Sensitivity, specificity, and false negative rate for 1,682,504 screening mammography examinations from 2007-2013.

12. Brill JV, Screening for Cancer: The Economic, Medical, and Psychosocial Issues, $A J M C$, November 16, 2020

13. Cancer.org, Can Kidney Cancer be Found Early, Cancer.org, 2020, February 1

14. Cancer.Org, Can Non-Hodgkin Lymphoma Be Found Early, Cancer.org, 2021

15. Chou R, Bladder Cancer in Adults: Screening, Ann Intern Med, 2010, 153:461-468

16. Clarke CA, Hubbell E, Kurian AW, Colditz GA, Hartman AR, Gomez SL. Projected reductions in absolute cancer-related deaths from diagnosing cancers before metastasis, 2006-2015. Cancer Epidemiol Biomarkers Prev. 2020; 29 (5):895-902.

17. Crépel M, Jeldres C, Sun M, Lughezzani G, Isbarn $\mathrm{H}$, Alasker A, et al. A population-based comparison of cancer-control rates between radical and partial nephrectomy for T1A renal cell carcinoma. Urology (2010) 76(4):883

18. de Carvalho TM, Heijnsdijk EA, de Koning HJ. Comparative effectiveness of prostate cancer screening between the ages of 55 and 69 years followed by active surveillance. Cancer. 2018; 124 (3):507-513.

19. Eaglehouse YL, George MW, Richard P, Shriver CD, Zhu K (2019) Costs for Colon Cancer Treatment Comparing Benefit Types and Care Sources in the US Military Health System, Military Medicine, Volume 184, Issue 11-12, NovemberDecember 2019, Pages e847-e855,

20. Elder C, How much does breast cancer treatment cost in the US? The check up by Single Care, 2017
21. Esselen KM, Feldman S. Cost-effectiveness of cervical cancer prevention. Clin Obstet Gynecol. 2013; 56 (1):55-64.

22. Ekwueme DU, Gardner JG, Subramanian S, Tangka FK, Bapat B, Richardson LC. Cost analysis of the National Breast and Cervical Cancer Early Detection Program: selected states, 2003 to 2004. Cancer (2008) 112(3):626

23. Farivar-Mohseni H, Perlmutter AE, Wilson S, Shingleton WB, Bigler SA, Fowler JE, Renal cell carcinoma and end stage renal disease, J Urol. 2006 Jun; 175(6):2018-20; discussion 2021.

24. Gilda TR, Byfield SD, Hogarth DK, Wilson DS, Quinn CC, A retrospective analysis of delays in the diagnosis of lung cancer and associated costs, Clinicoecon Outcomes Res, 2017; 9: 261-269.

25. Halpern JA, Chughtai B, Ghomrawi H. Costeffectiveness of Common Diagnostic Approaches for Evaluation of Asymptomatic Microscopic Hematuria. JAMA Intern Med 2017; 177:800-7.

26. Hollenbeck BK, Ye Z, Dunn RL, Montie JE, Birkmeyer JD, Provider treatment intensity and outcomes for patients with early-stage bladder cancer. J Natl Cancer Inst. 2009; 101: 571-580

27. Howlader N, Noone A, Krapcho M. editors. SEER Cancer Statistics Review. National Cancer Institute; (1975-2009)

28. Islami F, Miller KD, Siegel RL, et al. National and state estimates of lost earnings from cancer deaths in the United States. JAMA Oncol. 2019; 5 (9):e191460-e191460.

29. Kakushadze Z, Raghubanshi R, Yu W, Estimating cost savings from early cancer diagnosis. Data, 2017; 2(30): 2-16

30. Kim SY, Kim HS, Park HJ. Adverse events related to colonoscopy: global trends and future challenges, World J Gastroenterol. 2019; 25(2):190-204.

31. Losina E, Walensky RP, Geller A, Beddingfield FC, Wolf LL, Gilchrest BA, Freedberg KA, Visual Screening for Malignant Melanoma Costeffectiveness Analysis, Arch Dermatol. 2007; 143(1):21-28.

32. Marrero JA, Kulik LM, Sirlin CB, et al. Diagnosis, staging, and management of hepatocellular carcinoma: 2018 practice guidance by the American Association for the Study of Liver Diseases. Clin Liver Dis (Hoboken). 2019;13(1): MDSave, Mammogram Screening, 2020

33. Mayo Clinic Staff, PSA Test, Mayo Clinic Report, May 4, 2019

34. National Cancer Institute. Cancer screening. Updated April 9, 2018.

35. National Cancer Institute. Financial burden of cancer care. March 2020. 
"A Comparative Expected Value Analysis Study to Determine If the Economic Benefits of Screening and Early Diagnosis Treatment of the Most Common Types of Cancer in the United States Provide Economic Value"

36. O’Connell A (2015) Mammograms: Facts on False Positives, Health Matters

37. Parkinson R, Ramsey S, Aitchinson M, Kumar M, Parsons K. Letters in response to Turney et al 2006. BJU Int (2006) 97:1121-4

38. Patel N, Cranston D, Akhtar MZ, George C, Jones A, Leiblich A, Protheroe A, Sullivan M, Active surveillance of small renal masses offers short-term oncological efficacy equivalent to radical and partial nephrectomy BJU Int. 2012 Nov; 110(9):1270-5

39. Piepkorn M, Elmore J, Most mole biopsies are benign, says text analysis of EMRs, UW Medicine, Retrieved January 19, 2021.

40. Ran T, Cheng C-Y, Misselwitz B, Brenner H, Ubels J, Schlander M. Cost-effectiveness of colorectal cancer screening strategies-a systematic review. Clin Gastroenterol Hepatol. 2019;17 (10): 1969-1981.

41. Rosenberg, J, Prostate Cancer in Older Men Costs Medicare \$1.2 Billion Over 3-Year Period, AJMC, 2018

42. Sand B, Are all colon polyps precancerous or worse? Honor Health, 2020

43. Shrime MG, Goldstein MD, Seaberg RM, Sawka AM, Rotstein L, Freeman JL, Gullane PJ, Costeffective Management of Low-Risk Papillary Thyroid Carcinoma, Arch Otolaryngol Head Neck Surg. 2007;133(12):1245-1253.
44. Siegel RL, Miller KD, Jemal A. Cancer statistics, 2020. CA Cancer J Clin. 2020;70(1):7-30.

45. Subramanian S, Tangka FK, Hoover S, Cole-Beebe M, Joseph D, DeGroff A. Comparison of Program Resources Required for Colonoscopy and Fecal Screening: Findings from 5 Years of the Colorectal Cancer Control Program. Prev Chronic Dis 2019,16:180338

46. US Preventive Services Task Force. A and B recommendations. 2020.

47. Ward KK, Shah NR, Saenz CC, et al.: Cardiovascular disease is the leading cause of death among endometrial cancer patients. Gynecol Oncol , 2012, 126 (2): 176-9

48. WebMD, Understanding Colorectal Cancer -- The Basics, WebMD.com, 2021

49. WebMD, Should I delay treatment for B-Cell Lymphoma, WebMD, on July 01, 2020

50. World Health Organization. Guide to cancer early diagnosis. 2017.

51. Yu J, Blackford AL, dal Molin M, et al, Time to progression of pancreatic ductal adenocarcinoma from low-to-high tumour stages, Gut 2015;64:17831789.

52. Zappa C, Mousa SA. Non-small cell lung cancer: current treatment and future advances. Transl Lung Cancer Res. 2016; 5 (3):288-300.

\section{APPENDIX}

\begin{tabular}{|c|c|c|c|c|c|c|c|c|}
\hline $\begin{array}{l}\text { Types of } \\
\text { Cancer }\end{array}$ & $\begin{array}{l}\text { Cost to } \\
\text { Screen }\end{array}$ & $\begin{array}{l}\text { Positivity } \\
\text { Rate }\end{array}$ & $\begin{array}{l}\text { Expected Cost } \\
\text { to Screen }\end{array}$ & $\begin{array}{c}\text { Early Stage } \\
\text { Treatment } \\
\text { Cost }\end{array}$ & $\begin{array}{c}\text { Screen \& Early } \\
\text { Stage Treat Cost }\end{array}$ & $\begin{array}{c}\text { Late Stage } \\
\text { Treatment } \\
\text { Cost }\end{array}$ & $\begin{array}{l}\text { Economic } \\
\text { Benefit }\end{array}$ & USPTF \\
\hline Bladder & - & 1.300 & $\$ 50,000$ & $\$ 2,830$ & $\$ 52,830$ & $\$ 7,131$ & $(\$ 45,699)$ & $\mathrm{I}$ \\
\hline Breast & $\$ 214$ & 0.005 & $\$ 42,800$ & $\$ 60,637$ & $\$ 103,437$ & $\$ 115,396$ & $\$ 11,959$ & $\overline{\mathrm{BCI}}$ \\
\hline Colorectal & $\$ 3,450$ & 0.043 & $\$ 80,232$ & $\$ 14,924$ & $\$ 95,156$ & $\$ 100,404$ & $\$ 5,248$ & $\mathrm{AC}$ \\
\hline Endometrial & $\$ 1,500$ & 0.002 & $\$ 750,000$ & $\$ 13,421$ & $\$ 763,421$ & $\$ 13,421$ & $(\$ 750,000)$ & I \\
\hline Kidney & - & - & $\$ 88,000$ & $\$ 25,000$ & $\$ 113,000$ & $\$ 25,000$ & $(\$ 88,000)$ & I \\
\hline Leukemia & - & - & - & - & - & - & - & I \\
\hline Lung & $\$ 300$ & 4.000 & $\$ 7,500$ & $\$ 14,340$ & $\$ 21,840$ & $\$ 21,441$ & (\$399) & B \\
\hline $\begin{array}{c}\mathrm{NH} \\
\text { lymphoma }\end{array}$ & - & - & - & - & - & - & - & I \\
\hline Pancreatic & - & - & - & - & - & - & - & $\mathrm{D}$ \\
\hline Prostate & $\$ 1,240$ & 2.000 & $\$ 62,000$ & $\$ 19,901$ & $\$ 81,901$ & $\$ 50,276$ & $(\$ 31,625)$ & $\mathrm{CD}$ \\
\hline Skin & $\$ 536$ & 4.100 & $\$ 13,073$ & $\$ 1,732$ & $\$ 14,805$ & $\$ 56,059$ & $\$ 41,254$ & I \\
\hline Thyroid & - & - & $\$ 149,619$ & $\$ 14,559$ & $\$ 164,178$ & $\$ 115,680$ & $(\$ 48,498)$ & $\mathrm{D}$ \\
\hline
\end{tabular}

